\title{
PRES 2014: Dedicated to technologies for sustainable energy and product production
}

\author{
Zdravko Kravanja $^{1} \cdot$ Petar Sabev Varbanov $^{2} \cdot$ Jiří Jaromír Klemeš $^{2}$
}

Published online: 18 June 2015

(c) Springer-Verlag Berlin Heidelberg 2015

Our society is faced with several severe problems-population growth, environmental crisis, different forms of societal destruction, scarcities of resources, etc., to name some of the more important ones. All of them are interrelated which means that when one of them is deepening, the others are worsening too and vice versa. Solving these problems should therefore be regarded as the most important goal towards which we have to strive with persistent determination in order to save the world for future generations. Research and development should thus provide efficient and effective solutions including new inventions for achieving cleaner technologies and proficient environmental management. Due to the exponential growth of our civilization, requirements for basic resources-energy, water, food and raw materials for producing vast numbers of products - increase exponentially too giving rise to ever more frequent supply shortages.

The organisations of different conferences, symposiums, workshops and meetings, dedicated to sustainable development, are therefore highly appreciated. The Conference "Process Integration, Modelling and Optimisation for

Zdravko Kravanja

zdravko.kravanja@um.si

Petar Sabev Varbanov

varbanov@cpi.uni-pannon.hu

Jiří Jaromír Klemeš

klemes@cpi.uni-pannon.hu

1 Faculty of Chemistry and Chemical Engineering, University of Maribor, Smetanova ulica 17, 2000 Maribor, Slovenia

2 Faculty of Information Technology, Centre for Process Integration and Intensification - CPI2, University of Pannonia, Egyetem utca 10, Veszprém 8200, Hungary
Energy Savings and Pollution Prevention 2014" or PRES 2014 was one of them. The aim of this conference was to bring together people of different backgrounds-scientists, industrial experts, academics and students-to exchange and share the most recent knowledge about concepts, methods, tools and applications, either regarding continuous developments of existing technologies or innovative developments of new ones based on new discoveries and inventions. Out of 551 abstracts, prepared by 2133 authors from 57 countries, the PRES 2014 Scientific Committee selected 216 oral presentations, 33 being keynote, and four plenary lectures common for PRES and CHISA, and 233 posters. In particular, the contributions were devoted to sustainable biofuel production and use, integrated $\mathrm{CO}_{2}$ capture, sequestration and reuse, heat integration, water and energy integration, process integration and optimisation innovation, Total site and renewables, mass integration and separations, process integration for $\mathrm{CO}_{2}$ reduction, energy saving technologies, experimental studies, optimal design, integration of renewables, including supply chains, waste minimisation and waste to energy, electricity, power and CHP, more efficient operations, knowledge management and transfer, sustainable production, industrial applications, energy efficiency and clean production in industry, low emission technologies, and EU projects and green energy. 41 invitations were sent to the PRES 2014 authors to prepare extended manuscripts of which 22 are finally being published in this Special Issue of Clean Technologies and Environmental Policy, following a strict journalistic reviewing process. The presented papers can be classified into the following groups:

(i) Green energy and product productions

(ii) Environmentally friendly, healthier and safer technologies and processes 
(iii) Advances in $\mathrm{CO}_{2}$ capturing, storage and recycling, and

(iv) Sustainability assessment in decision making

The PRES 2014 conference was the 17th conference since its inception in Prague in 1998. PRES 2014 was organised jointly with CHISA 2014 <www.chisa.cz/2014> in Prague from 23rd to 27th August 2014. Preparation and organisation are currently going on for the next eventPRES'15, which will be held in Borneo at Kuching, Sarawak, Malaysia <www.conferencepres.com $>$ from 22nd to 27th August 2015. This conference is of significant interest as it will be the first PRES conference held in Asia, where there has been growing interest from scientists, academics, industrial professionals and students for process integration and sustainable development over the last decade. The present number of submitted abstracts has reached 400 .

This Special Issue of Clean Technologies and Environmental Policy has been published within a rather short period which would not have been possible without valuable help from about 60 reviewers who have selflessly spent a great deal of their efforts on adjusting the professional qualities of the submitted manuscripts to the high standards of the journal. As guest editors of this Special Issue, we would like to thank all of them and especially those engaged in multiple reviewing and also involved in the PRES 2014 Scientific Committee. 